\title{
Representaciones mediáticas. Tres notas sobre los procesos semióticos en los medios masivos
}

\author{
Media representations. Three notes on the semiotic processes in the \\ mass media
}

\author{
Julio Horta \\ Universidad Nacional Autónoma de México \\ julio_horta@hotmail.com
}

\begin{abstract}
Resumen
El presente trabajo busca dar cuenta de los procesos semióticos e interpretativos implicados en la ambigüedad de las representaciones mediáticas y, en particular, de la noticia y de las diferentes formas de construcción-difusión de la información. Por ello, se considerará la difusión masiva de la información y el ejercicio periodístico como un proceso semiótico en la construcción de una realidad ficticia. En este sentido, se busca dar cuenta de la representación mediática, considerándola como la contraposición del carácter uniforme de la expresión masiva (contexto de producción) y la diversidad de interpretaciones (contexto de recepción). Esta revisión analiza ambos componentes, los cuales son el sustento concreto que permite al individuo significar los contenidos sociales ajenos, mediados e intencionados, propiciando con ello un fuerte sentido de pertenencia social.
\end{abstract}

Palabras Clave: Semiótica, cultura mediática, información, interpretación, representación.

\begin{abstract}
This paper seeks to give an account of the semiotic and interpretive processes involved in the ambiguity of media representations and, in particular, of news and of different forms of construccion-difusion of information. For this reason, it is deemed the massive dissemination of information and journalistic exercise as a semiotic process in the construction of a fictitious reality. In this regard, it is sought to account for the media representation, as the contrast of the uniform character of the mass expression (context of production) and the diversity of interpretations (context of reception). This review examines both components, which are the concrete support that allows the individual to mean social content non-, mid-, and intentional, thereby fostering a strong sense of social belonging.
\end{abstract}


Keywords: Semiotics, culture media, information, interpretation, representation.

\section{INTRODUCCIÓN}

Dentrodelprocesoglobalde información, un tema interesante es considerarla difusión masiva y el ejercicio periodístico como un proceso semiótico en la construcción de una "realidad" coherente. Para aceptar esta afirmación, en principio, hay que considerar que la forma de esta "realidad" está determinada por representaciones (signos) cuyos sentidos están condicionados por contextos sociales específicos. La noticia es considerada dentro de este planteamiento como representación mediática, que sintetiza la complejidad del hecho en unidades lingüísticas (o en su defecto, unidades no verbales susceptibles de ser leídas de manera lingüística, como las fotografías, videos, etc.).

Esta representación es una expresión significativa que depende del contexto de producción, y cuya finalidad está depositada en la pretensión de "informar" a un alguien. Pero esto solo es la mitad del proceso. Para que en efecto se dé forma a algo -in-formar- se requiere de un otro que interprete lo representado dentro de un contexto social de recepción. La relación de elementos implicados en ambos contextos (producción-recepción) nos lleva hacia una construcción ambigua en la imagen del presente.

La noticia, como forma discontinua del hecho social, es asimismo una unidad mediática determinada, producida al interior de una sociedad en particular: es decir, "es una representación social de la realidad cotidiana, producida institucionalmente, que se manifiesta en la construcción de un mundo posible” (Gomis, 1991, p. 41). Este mundo posible es generado por la probabilidad de una representación cuya función primordial es construir una imagen: a saber, la autoreferencia social del presente, entendida como la conciencia colectiva capaz de generar conocimiento de los hechos presentes y pertenencia social del individuo en su sociedad.

Pero es precisamente el carácter ambiguo de la noticia lo que permite la formación autoreferente. En palabras más extensas, la representación mediática se articula sobre la contraposición del carácter uniforme de la expresión masiva (contexto de producción) y la diversidad de interpretaciones (contexto de recepción). Ambos componentes son el sustento concreto que permite al individuo significar los contenidos sociales ajenos, mediados e intencionados, propiciando con ello un fuerte sentido de pertenencia social.

Empero, la conformación mediática del sentido de pertenencia nos permite mirar de manera problemática el proceso de semiosis que ocurre en la interrelación de los signos que constituyen los mensajes-texto que se difunden a través de los medios 
masivos. En una primera instancia, la interpretación y apropiación individual de la información (dentro de un contexto de recepción particular) nos permite afirmar la "semiosis hermética" ${ }^{1}$, como un tipo específico de significación que tiende hacia una relación semántica que se extiende indefinidamente (sin límites y a la "deriva") siempre hacia algo diferente.

Tomando en consideración lo anterior, el presente trabajo busca dar cuenta de los procesos semióticos implicados en la ambigüedad de las representaciones mediáticas. En un primer momento, se aborda la noticia como representación generada por la interpretación dentro del contexto de los medios masivos, y con ello dar cuenta de algunos planteamientos implicados en su producción. De este sentido reflexivo se desarrolla, en un segundo momento, el carácter problemático vislumbrado en la construcción mediática de un mundo posible circunscrito en el contexto de recepción.

En un tercer momento se aborda el fenómeno de la desmasificación mediática, lo cual conduce hacia la polarización de significados y la multiplicación de contextos interpretativos. Para que a partir de ahí se realice, finalmente y a manera de conclusión, una breve reflexión acerca de las condiciones y elementos semióticos implicados en los procesos de transmisión de la información, para de esta manera hacer un esbozo acerca de la semiosis implicada en la difusión masiva.

\section{PLANTEAMIENTO I. REPRESENTACIÓN, INTERPRETACIÓN Y CULTURA MEDIÁTICA}

En las diferentes teorías del lenguaje, uno de los problemas nodales está en la designación de la referencia (objeto) y significado de los signos. La relación específica entre estos dos elementos nos lleva a considerar el problema acerca de los límites del sentido. En realidad, cualquier texto discursivo evidencia, por un lado, una necesidad esencial del hombre (significar), y por otro, muestra ámbitos diversos dentro de una misma realidad cultural (representar). La relación del signo con su referenciasignificado es problemática, pues supone que signo y objeto son entidades que existen por sí mismas de manera independiente a todo contexto social. Pero, además, implica reducir la complejidad del lenguaje humano a un carácter instrumental, donde los signos-palabras son herramientas a través de las cuales analizar $y$, por ende, conocer una realidad que está dada.

El acercamiento a la tradición moderna del lenguaje, y en consecuencia a la semiótica, nos permite vislumbrar el valor cognitivo del lenguaje verbal. En esta

1 Es decir, la relación de significación en razón de relaciones analogías y semejanzas. Cfr. Eco, 1992, p. 364 y ss. 
tradición, el lenguaje verbal (palabras) es el que constituye la significación y, desde ahí, posibilita un significado de las cosas desde su propio carácter como conocimiento previo, pues permite la organización de los objetos; supone y plantea un tipo de relación entre estos; y establece el carácter cognitivo de las representaciones. En este sentido, la función del lenguaje es clara: el elemento lingüístico sobre la experiencia social permite establecer observaciones con sentido que muestren el significado de lo observado.

$\mathrm{Si}$ consideramos estas reflexiones, podemos aceptar sin menoscabo la caracterización del periodismo que sostiene Gomis (1991): un proceso de interpretación que, si bien surge de la investigación social, supone asimismo que la realidad (continua) puede reducirse en fragmentos comunicables (discontinuos). El sustento de este proceso es el "hecho periodístico", el suceso social visto como unidad independiente y completa que se realiza en la experiencia dentro de una sociedad. Como resultado de diversas interpretaciones sucesivas, se produce la noticia en tanto reducción de la complejidad del hecho a una unidad formal de lenguaje. Así pues, en el procedimiento que va del hecho a la noticia ocurren diferentes "operaciones lingüísticas” a través de las cuales el continuum de la realidad puede ser formado en unidades discretas.

Este proceso de interpretación propuesto por Gomis nos sugiere considerar el carácter sintético de las representaciones como punto central dentro de la reflexión acerca del conocimiento mediático. Antes bien, una línea importante de los estudios filosóficos sobre el lenguaje $e^{2}$ fijarían el sentido de representación dentro del proceso cognoscitivo que ocurre en la estructura del sujeto: dentro de la cual el término representación es delineado como determinación y ordenamiento subjetivo de la multiplicidad proveniente de las sensaciones externas, como un acto de carácter sintético necesario para la construcción de conocimiento. Y es precisamente este planteamiento el que interesa retomar en relación con el periodismo, pues la noticia, como unidad de sentido, produce una particular representación cuya función es generar conocimiento ${ }^{3}$ de un mundo posible, que surge del tejido cotidiano de la realidad social.

El proceso de interpretación no es abierto ni individual, está condicionado por un contexto de producción: la construcción de un mundo posible está determinada por los intereses de las instituciones-empresas que han convertido la información en un bien económico, mediatizando los contenidos y dirigiendo los mensajes - a la manera

2 Estudios cuya beta está en razón de los planteamientos aristotélicos y kantianos.

3 Por supuesto, no conocimiento en el sentido fuerte de la expresión kantiana, es decir, no un conocimiento como juicio sintético a priori. Pero ciertamente se puede dejar a un lado este problema, y hablar de conocimiento como representación que, a un cierto nivel de ordenamiento, construye una conciencia social como conocimiento de sí mismo, auto-referencia del presente. 
de McLuhan (1991)-. La noticia se edifica sobre la base de intereses económicos de la era industrial, y sus contenidos traducen la diversidad social en representaciones específicas que buscan justificar y fortalecer el modo de producción capitalista a nivel global. Producen como efecto inmediato narcosis y pasividad sociales, a través de los cuales instituyen su poder como industria, incluso condicionando la fuerza de los medios de producción, dirigiendo las dinámicas de mercado y generando redes de consumo.

En este contexto, se asiste a una dialéctica compleja donde los medios masivos de información (comunicación) surgen de manera necesaria en la era industrial, pero asimismo determinan la dinámica de explotación del capital. En consecuencia, construyen la representación del mundo capitalista, y al mismo tiempo condicionan la producción de bienes, instituyendo la representación de su producto (la información, la noticia) como el bien de mercado mejor valorado.

Por supuesto, la dinámica capitalista apuntó hacia la consecuente extensión territorial del mercado, y con ello

al avanzar sobre un país tras otro, destruyó este monopolio de las comunicaciones (monopolio sustentado por el núcleo familiar de sociedades feudales). No ocurrió esto porque los ricos y poderosos se volvieran súbitamente altruistas, sino porque la tecnología de la segunda ola (era industrial) y la producción en serie de las fábricas necesitan movimientos masivos de información (Toffler, 2000, p. 50).

Provenientes de la matriz de la fábrica, los medios masivos de información accionaron bajo los parámetros de la producción en serie y, por tanto, del consumo en serie. Esto último los perfiló en paralelo a lo que Toffler llama "principios de la sociedad industrial": "sincronización" del tiempo social de acuerdo con los horarios industriales; "concentración” del espacio geográfico, del trabajo, de los energéticos, y la economía, en determinadas áreas; "maximización” del imaginario en la ocupación del espacio; "centralización" del poder, y su consecuencia el monopolio.

Pero, por encima de cualquier otro, dos fueron los principios esenciales del industrialismo que propiciaron las transformaciones de las formas expresivas: por un lado, la "especialización”, la cual redujo el abanico de posibles relaciones humanas, incluso en el ámbito de la educación, a la dicotomía productor/cliente; por el otro, la "uniformización”, de principio comercial/administrativa, pero cuya consecuencia trajo la uniformización de los lenguajes, en detrimento de los dialectos regionales, sustituyendo así los idiomas "no-uniformados" por los "uniformados" en términos de mercado (inglés o francés).

En el ámbito de los medios masivos, la uniformización implica, además, la uniformización de los posibles comportamientos y relaciones sociales en la composición de los mensajes. De ahí que los objetos - de innegable sustento cultural- 
empleados como factores de mercado, o bien como objetos mismos de consumo, adquieren una representación diferente en tanto son extraídos de su contexto cultural inicial, el cual los hace presentes dotándolos de sentido, para ser re-presentados en un contexto mercantil que, de principio, resulta opuesto al contenido cultural inicial del objeto.

Este proceso lo precisa Matterlart, al hacer una revisión de las propuestas teóricas de Horton Cooley:

con la difusión sin límites de las ideas ... en vez de la individualidad que era estimulada por los obstáculos anteriores, se tendría una 'asimilación universal', al ser inducida cada localidad a adoptar las mismas modas, desde los vestidos hasta la lengua... Esta uniformidad exterior no sería más que el signo visible de la correspondiente nivelación de las ideas (Mattelart, 2000, p. 301).

En otras palabras, la representación mediática asiste a las necesidades experienciales propias de una cultura que ha sustituido la situación y la experiencia por la dispersión espacial, en tanto mantiene como esencial el factor de inmediatez en el proceso comunicativo. Es decir, las necesidades de una cultura cuyas fuentes de experiencia social son buscadas y valoradas en alto grado, en la explosión informativa que otorgan los medios masivos: cultura mediática, pues, donde las experiencias son "mediadas", y no vividas.

Pero la uniformización mediática tiene otras implicaciones a considerar, la "imposición” y "dominación”. En efecto, ahí donde las formas y usos de un lenguaje existen a la par que otras formas y usos de otro lenguaje, no siempre se da una coexistencia armoniosa y enriquecedora entre sus hablantes; por ello, aparecen procesos político/sociales de unificación e integración lingüística en las representaciones mediáticas.

Pero, en virtud de que la integración "es un producto de la dominación política constantemente reproducida por instituciones capaces de imponer el reconocimiento universal de la lengua dominante, constituye la instauración de relaciones de dominación lingüística” (Bourdieu, 1985, p. 20). Asimismo, este tipo de relaciones impulsa una serie de limitantes, entre las que cabe destacar el acceso diferenciado a las instituciones; de suerte que no todos los hablantes tienen la posibilidad de integrarse a esa comunidad, ni mucho menos participar con sus propias modalidades expresivas en su construcción.

En realidad, los fenómenos de imposición, dominación, marginación y discriminación, han sido recurrentes en el proceso de la comunicación humana. Pero, de manera particular, el desarrollo de los medios masivos, que en lugar de constituir una nueva forma de comunicar orientada hacia la liberación de las estructuras hegemónicas - que centralizan e imponen el capital verbal y comunicativo 
dominante-, ha promovido prácticas modernas de imposición y dominación que se nutren de la racionalidad industrial y se materializan en la circulación mercantil de toda producción simbólica (desde las tradiciones ancestrales hasta el discurso sobre la tecnología de punta; desde los acontecimientos masivos hasta sucesos anecdóticos de vidas individuales).

Pero, más allá del asunto de las estrategias comunicativas, el problema de la racionalidad mercantil no solo se circunscribe a la construcción simbólica de los medios controlados por publicistas y mercaderes, se extiende a los ámbitos de la vida cultural, social e individual; se incrusta en las instituciones como la familia, la educación, el Estado; se manifiesta en los discursos oficiales y académicos. En fin, aunque no toda la cultura social es mediática, ni termina en el discurso mediático, sus pretensiones globalizadoras están impactando seriamente en los sentidos y significaciones de la vida humana; en la definición de las formas de imaginar la realidad, de construir un relato sobre las sociedades, de contribuir a la educación emocional y política de los públicos.

En efecto, las pretensiones democratizadoras, liberadoras e igualitarias, de los partidarios del consumo mediático cultural, subrayan las posibilidades ilimitadas que ofrece la difusión de información a través de los medios masivos, al señalar que para acceder a estos no se requiere saber leer ni escribir como tampoco pertenecer a determinado grupo, comunidad o localidad. Así pues, la forma en que se organizan las secuencias y los códigos que se utilizan en las noticias permiten su apertura a todos los públicos reales y posibles.

Pero, en todo caso, se olvidan que la interpretación se realiza desde determinadas experiencias sociales a partir de las disposiciones grupales e históricas; y por lo tanto, esta misma interpretación se encuentra limitada por las perspectivas particulares: por el acceso de alternativas de información; por las competencias lingüístico/ cognoscitivas (como el aprendizaje de la lectura, los hábitos operativos para desarrollar facultades y capacidades selectivas, judicativas, argumentativas y reflexivas); además de las fuentes de información y de conocimiento, que tienen un papel preponderante en el desarrollo de competencias visuales, sobre todo las relacionadas con la lectura de las imágenes.

Sin embargo, el consumo simbólico no es privativo de la cultura mediática, pues en la historia de casi todas las sociedades que han sido objeto de estudio por antropólogos se ha identificado, en esa práctica, una función hedonista: es decir, el disfrute de la contemplación de los objetos de consumo, el placer o displacer experimentado por la posibilidad o imposibilidad de su adquisición. Igualmente, el consumo permite y propicia la simulación de estatus cultural, porque las preferencias, las elecciones y las mismas mercancías, crean la ilusión de semejanza con la gente y posiciones sociales de los sujetos que se aprecian como culturalmente valiosos. 
Sin embargo, dentro de la racionalidad industrial y la consecuente cultura mediática, todos los símbolos primarios que permiten la referencia al mundo, la expresión de sentimientos y la formulación de juicios, se trastocan, rediseñan y mezclan, de tal manera que al final de esta operación interpretativa se presentan sin sus contenidos y sentidos originarios.

\section{PLANTEAMIENTO II. EL CONTEXTO DE RECEPCIÓN Y LA PRODUCCIÓN DE SENTIDO}

Se ha descrito en las líneas anteriores el carácter de las representaciones mediáticas dentro de un proceso de interpretación, cuyo resultado es formar representaciones institucionalizadas que condicionan el mundo de los individuos; esto nos lleva a considerar la otra parte del proceso desde un punto de vista semiótico, a saber, el contexto de recepción dentro del espacio de la significación social4.

Para caracterizar la cultura mediática y las sociedades de la información, McLuhan (1991) recurre al término "aldea global" para plantear la necesaria integración de la sociedad en comunidades globales, donde la información fluye indistintamente en todos los estratos y grupos por efecto de los medios masivos. Sin embargo, habría que tomar distancia al respecto. La mediatización de las representaciones, más que integración, implica distanciamiento: espacial, en primera instancia; pero mental, y por tanto cultural, en tanto se dificulta la posibilidad de la conciencia social generada en la convivencia situacional.

La propuesta de McLuhan resulta necesaria porque, de alguna manera, a través de sus generalizaciones nos ha mostrado aquello que tiende a ser olvidado en el estudio del proceso comunicativo: a saber, que el carácter significativo de las representaciones mediáticas no es uniforme, ni lineal, sino que depende de los diversos contextos en coyuntura (social, cultural, escolar, etc.), que vienen a semantizar de manera diferenciada los múltiples contenidos mediatizados.

Una consecuencia visible es la construcción de objetos llamados "kitsch". En palabras de Abraham Moles, "el objeto kitsch se define por una alteración en su funcionalidad ... posee una funcionalidad indicada, pero cumple con una función sobreañadida, suplementaria, noincorporada desde el principio enla función, y que fue insertada artificialmente por el intermediario” (Moles, 1974, p. 154). Y, por supuesto, en las sociedades industriales modernas, donde los intermediarios inmediatos son

4 En esta reflexión se entiende por significación la relación entre expresión y contenido, a la manera como ha sido determinada desde la lingüística estructural. Sin embargo, dicha relación se circunscribe al problema del contexto social que a fin de cuentas determina los posibles sentidos de los signos. 
los medios masivos, se puede afirmar que la notica, como representación mediática, está conformada por objetos kitsch, pues los diferentes elementos que articulan al hecho periodístico como forma-noticia son objetos cuya función significativa ha sido sobreañadida, edificando así una suerte de significado artificial diferente al significado inicial del hecho.

En el hecho periodístico los significados están en el orden de la experiencia, vinculados con el carácter significativo de la vivencia particular. Pero en la noticia, los significados derivados de objetos mediatizados y con funcionalidad indicada, son artificiales para un individuo en razón de sustentarse sobre la base del sesgo existente entre la representación mediada y el contenido vivencial inmediato.

La distancia que supone un contenido artificial mediático no nos conduce necesariamente a una lectura uniforme (como se podría deducir a partir de considerar las reflexiones anteriores sobre la representación mediática). En todo caso, evidencia la ausencia significativa que motiva la intervención de un sistema externo desde el cual realizar una lectura interpretativa. En este orden, se puede advertir que la cultura constituye el contexto de interpretación en la recepción: una urdimbre en la cual se establecen relaciones entre signos que se encuentran circunscritos al mundo cultural propio; en otras palabras, está en un ámbito conformado por vínculos simbólicos y representativos entre sujetos y objetos culturales que constituyen el entorno humano.

En esta línea de investigación, los componentes del acto comunicativo (signos, hablantes y contextos) se consideran estrechamente vinculados con la esfera sociocultural; en términos amplios, la cultura es definida como el lenguaje de una sociedad, con signos y sentidos propios, compuesta por diferentes sistemas de significación. En razón de estos planteamientos, se sostiene la posición de semiólogos como Umberto Eco, quien al respecto concluye: "la cultura por entero debería estudiarse como un fenómeno de comunicación basado en sistemas de significación” (Eco, 2000, p. 58).

Luego, a partir de la atención en los objetos que conforman las representaciones mediáticas, se abre, por un lado, una vía de aproximación para identificar, caracterizar y delimitar el mundo cultural; por otro, un campo de indagación donde pueden adaptarse técnicas de investigación semiótica, porque -asintiendo con Abraham A. Moles- "la noción misma de objeto está unida a una semiótica puesto que el objeto es manipulado conceptualmente a partir del nombre que sirve para designarlo" (Moles, 1974, p. 9).

En este tenor de ideas, resulta pertinente subrayar que cuando se usa el lenguaje para designar objetos, las palabras no solo sirven para denominar el objeto per se (cosas), sino más bien se convierten en transmisoras de contenidos culturales que se organizan en diversos niveles de significación. Estos objetos o "artificios significantes" (Eco, 2000, p. 66), organizados en estructuras significativas, dan forma y contenido a las unidades de una cultura determinada, y asimismo constituyen una organización o visión del mundo, condicionada por la mentalidad que impera en los sujetos que 
habitan ese mundo específico. Por lo tanto, se puede considerar que el objeto es comunicación, pues el lenguaje lo convierte en "un mensaje de un individuo a otro, de lo colectivo ... a lo personal” (Eco, 2000, p. 65).

Así, pese a la tendencia globalizante de los mensajes masivos, la consideración de la cultura como sistema de significación, a través del cual se interpretan las representaciones y sus objetos, nos coloca en una posición contraria a la sentencia "el medio es el mensaje” planteada por McLuhan (1996). En efecto, pues si los límites de la significación están trazados dentro del contexto cultural desde donde se recibe el mensaje, y si ciertamente cada sistema cultural supone relaciones significativas diferentes, entonces la lectura del mensaje es problemáticamente diversa.

Pero esta diversidad es asimismo una consecuencia del proceso mismo de la globalización. En virtud de la dispersión espacial en la transmisión de información, generada por los medios masivos a partir de la extensión transoceánica de los mercados (internacionalización), y con el paulatino establecimiento de organismos y empresas de presencia multinacional (transnacionalización), la globalización se ha desarrollado como "un nuevo régimen de producción del espacio y del tiempo... más que un orden social o un único proceso, es resultado de múltiple movimientos, en parte contradictorios, con resultados abiertos, que implican diversas conexiones 'local-global' y 'local-local”' (García, 1999, p. 47). Esto nos permite llegar hacia un sustento crítico de la cultura mediática global desde la diversidad cultural.

La respuesta a este fenómeno mediático globalizador no se ha hecho esperar. En efecto, el mundo contemporáneo también se ha convertido en escenario de propuestas, experiencias, iniciativas y prácticas, que se están dando a conocer bajo diversas denominaciones; como la llamada comunicación comunitaria, o también regional, o más aún democrática, entre otras más.

Esas designaciones se han empleado para nombrar propuestas teóricas alternativas de comunicación, e igualmente como identificadores de prácticas dirigidas al uso de la tecnología audiovisual, pero puesta al servicio social de comunidades locales: esto es, que respondan a los intereses y necesidades de cada región, comunidad, localidad, y cuyas fuentes de información, de representación, de narración, surjan de sus propias realidades, tradiciones e instituciones. En suma, donde la voz de cada comunidad tenga un espacio para hablar con sus propias formas de manifestación y en sus mismas modalidades de realización y, asimismo, el derecho a acceder a los "mercados oficiales", para poder desarrollar la competencia comunicativa de la lengua dominante.

Desde luego, en esas posturas se hace evidente la confrontación clásica entre tradición y modernidad; de hecho, cuando nuevas formas culturales impactan las tradicionales, se produce una tensión entre "el deseo de coherencia y continuidad, por un lado, y el deseo de dinamismo y contemporaneidad, por otro lado” (Geertz, 1997, p. 10).

Así, en el caso de la comunicación comunitaria, se busca emplear aquellos aspectos, escenarios y herramientas que la tecnología audiovisual ofrece, para 
producir y difundir formas simbólicas regionales o locales originadas en sus tradiciones. Aquí se usan instrumentalmente formas mediáticas, para dar valor y sentido a sus propias formas de manifestación y modalidades de realización lingual, en los mercados simbólicos oficiales. En general, se pretende utilizar el discurso mediático manteniendo su propio discurso en la redefinición del significado, sentido y valor de sus propias dinámicas comunitarias.

En relación con los medios masivos, con sus propios matices, pero siempre dentro del marco de la cultura mediática, estos manipulan todo tipo de producción simbólica -social y tradicional- para uniformar y estandarizar modos diversos de vida, bajo la hegemonía de un macrosistema tecno-económico. Frente a esta circunstancia, los nuevos medios locales utilizan instrumentalmente las formas de la comunicación masiva, con la intención de validar y darle sentido a sus representaciones propias, en los diversos contextos culturales (locales o regionales), para poder "vencer las resistencias a la estandarización universal" (Mattelart, 2000, p. 414).

De ahí que, en síntesis, lo que se busca, particularmente en el ámbito de la diversidad cultural, es la escenificación de la diversidad interpretativa a la que están sujetos los mensajes mediáticos, pero siempre dentro de los límites de este discurso mediático.

\section{PLANTEAMIENTO III. COMUNICACIÓN DESMASIFICADA}

La dispersión espacial en la transmisión de información, generada por los medios masivos, se convirtió en tierra fértil para un proceso consecuente: la "desmasificación mediática” (Toffler, 2000). Si por una parte es necesario considerar la globalización como una consecuencia inevitable de la sociedad industrial; entonces, en este sentido, los medios de información son componentes que permanecen inmersos en este "globo" capitalista, encontrándose dentro de este proceso. Empero, la dinámica de desarrollo del sistema capitalista presenta una contradicción: la consecuente desmasificación en los instrumentos de difusión masiva y, desde ahí, la particularización de la información.

Los medios masivos se encuentran inmersos en una dinámica diferente del sistema industrial centralizador que les dio origen. Como consecuencia de su función unificadora del globo "los medios de comunicación de masas lejos de extender su influencia, se ven de pronto obligados a compartirla. Están siendo derrotados en muchos frentes a la vez por lo queyo llamo los medios de comunicación desmasificada” (Toffler, 2000, p. 206).

Sin embargo, la desmasificación no es un proceso aislado; sino que está circunscrita al proceso global de fragmentación y descentralización de las instituciones capitalistas. En esta dirección, de acuerdo con Bauman (2002), las sociedades contemporáneas 
asisten a la fluidificación de las sólidas estructuras institucionales: así, mientras que las instituciones modernas en siglos anteriores se cimentaban sobre la base de la centralización del poder (con lo cual se apostaba por la imagen "artificial" de una vida regulada, "controlada y predecible") las formas sociales de organización y administración contemporáneas se rigen por una dinámica "líquida”, en la cual la confianza en la institución, como reguladora de las acciones individuales, se ha movilizado y diversificado hacia la individualización (siempre cambiante e incierta).

A nivel de semiosis cultural -en la generación de significados y sentidos- las repercusiones de este proceso marcan nuevas modalidades de apropiación y generación de la información significativa y, en consecuencia, nuevas maneras de formar una identidad social. En este sentido, se ha generado una sinergia social en donde cualquier persona es capaz de construir, potencialmente, su propio medio; proliferando, así, la multiplicidad de medios informativos locales. Con la creciente diversificación de medios se gestó, por tanto, una dispersión de la información; generando con ello una multiplicidad de imágenes del mundo; realidades que integran, en el último de los casos, una continuidad real, solo existente de forma tangible en la diversidad de sistemas y medios de información virtuales (masivos, pero además electrónicos).

Esta continuidad cambia sustancialmente las formas de expresión y relación humanas: el desarrollo tecnológico de las redes y sistemas comunicacionales ha cerrado el ciclo de información, dotando a los medios de una renovada capacidad para dar y recibir respuestas. Se materializa entonces la propuesta teórica de la retroalimentación, formando con ello una imagen de trascendencia social, el pináculo de las ideas globalizadoras: la simulación de interacción social.

A la luz de esa interacción, los discursos mediáticos de carácter informativo y periodístico se comprenden como una representación funcional mediática: representación en tanto se realiza en el marco de las posibles formas significativas de expresión, que establecen relaciones mediáticas en la continuidad de realidades posibles; funcional, en tanto cumple con los factores de inmediatez y acercamiento virtual; $y$, sobretodo, mediática, pues al ser una forma de expresión requiere de los "medios materiales" para su realización.

Dentro de este espacio, en el mundo informativo de los medios electrónicos la medición de audiencia se constituye en un criterio que regula y decide sobre las expresiones sociales que deben, tienen, y pueden ser consumidas por los diferentes grupos sociales. Dentro de esta lógica, los espacios virtuales donde se difunde la información buscan apropiarse de todos aquellos eventos que, en el ámbito de la "realidad" pública y privada, nacional e internacional, representen mercancías de consumo, pero que, en tanto mercancías, no generan plusvalía en términos de capital, sino en términos de su valor de uso en razón del disfrute o placer que puedan provocar en el observador. 
De suerte que, el ciberespacio se ha constituido en el ámbito donde se decide y difunde lo que es digno de verse públicamente, desde la intimidad que produce el anonimato detrás del ordenador. Y así también, se ha solidificado (paradójicamente) como el gran espacio donde las imágenes de realidad en una sociedad global -pero diversificada - se trastocan para rediseñar la tesitura decorativa en la continuidad tangible de un mundo virtual.

Siguiendola reflexión de Bauman (2002), el desarrollo de las sociedades modernas se enraizó sobre una metáfora de integración: la "sociedad". Esta forma significativa condicionó maneras de pensar la articulación de los sujetos como unidad necesaria, como el modo de vida social. Por ello, "la metáfora de sociedad utiliza las imágenes de cercanía, de proximidad, de estar juntos y de comprometerse los unos con los otros" (Bauman, 2002, p. 140). La función de la metáfora, en tanto recurso discursivo, está en determinar y reducir la complejidad de la experiencia social y, desde ahí, determinar un sentido posible entre elementos de naturaleza diferente u opuesta. En este sentido, la metáfora de la sociedad logra integrar la naturaleza contingente e individual de los sujetos sociales, bajo los términos de unidad y cohesión social.

Siconsideramos estaposición comofundamentodela reflexión, entoncespodemos llegar a una explicación semiótica que integre los tres procesos antes descritos: a saber, las nuevas dinámicas sociales nos muestran nuevas formas metafóricas con las cuales describir y dar cuenta de los hechos sociales contemporáneos. En consecuencia, puede sostenerse que la cultura mediática (masificada y desmasificada) se define en razón de una nueva metáfora: la "individualización”. Esta nueva forma significativa en las culturas modernas contemporáneas es resultado -una vez más, siguiendo a Bauman- de un sentimiento de "extrañeza", ya que los sujetos que convergían en un mismo espacio no se sentían en compañía, pues la "compañía” era, más bien, un sentimiento moral y no un estado físico.

La metáfora de la "individualización” funciona bien para describir el proceso mismo de generación y difusión de la información, pues si bien se ha dicho junto con Gomis (1991) que esta última surge de un proceso de interpretación, el resultado de este proceso (noticias, discursos, imágenes, etc.) adquiere significado solo dentro de una esfera de sentido privada e individual. La apropiación de la información, dentro de un espacio individual, tiene como consecuencia que la experiencia compartida sea innecesaria y, por tanto, solo virtual y contingente. Lo necesario, entonces, es la constitución de ese espacio de sentido individual, donde los sujetos aislados determinen aquello que tiene valor significativo y, como consecuencia, merece ser interpretado. Esto nos lleva a sostener la experiencia individual como la unidad y fundamento del sentido social; misma que, paradójicamente, solo puede ser compartida de manera virtual: es decir, en tanto espacial y temporalmente no determinada, contingente y dispersa.

Al final, la experiencia individual hace borrosa la referencia compartida, difumina 
la idea de realidad construida de manera convencional y, desde ahí, se vuelve el fundamento de la ilusión mediática: una ilusión sustentada en la irrealidad de cada experiencia particular - pues lo real es, necesariamente social- que se vive como real y verdadera desde el abrigo del anonimato de cada individuo.

\section{A MANERA DE CONCLUSIÓN: CONSIDERACIONES SOBRE EL PROCESO DE SEMIOSIS EN LOS MEDIOS MASIVOS}

Los procesos implicados en la difusión mediática, tanto masiva como desmasificada, implican de manera necesaria la diversificación de los contextos de recepción y, en esta dirección, la individualización en la interpretación de los mensajes-texto. Sin embargo, esta afirmación, más que determinante es en todo caso problemática: nos obliga a dar una respuesta en términos de la conformación del sentido en los medios masivos y la consecuente interpretación de este contenido.

En términos generales, la difusión e interpretación masivas de mensajes mediáticos nos lleva a considerar hipotéticamente el proceso mediático de conformación de sentido social como parte de una "semiosis hermética", en la cual, a partir de relaciones de analogía, las representaciones mediáticas adquieren su significado estableciendo un vínculo de semejanza con el objeto representado. En este punto, se hablaría (a partir de Ch. S. Peirce) de relaciones icónicas: donde el signo (o conjunto de signos relacionados entre sí a la manera de un texto-mensaje-discurso) representa alguno o algunos de los atributos o propiedades del objeto representado.

De aceptar esta afirmación, se estaría sosteniendo no solo que los medios masivos difunden la información a través de relaciones icónicas, sino que además se daría una solución determinante a la cuestión de la objetividad y veracidad de la información transmitida. A fin de cuentas, si las representaciones mediáticas son de carácter icónico, entonces la relación semántica entre el mensaje-texto y su contenido tendría garantizada su verdad en virtud de la semejanza entre el objeto de referencia y el signo (o signos) que lo representan. De ahí que resulte inevitable suponer que los sujetos sociales son, desde su contexto social particular, intérpretes legítimos de los mensajes mediáticos; por tanto, cada uno estaría justificado en construir su propia verdad acerca del hecho representado en tanto logre interpretar las relaciones icónicas, necesarias para entender el contenido del mensaje.

Pero la "semiosis hermética" lleva hacia una extensión desproporcionada del sentido, donde el sentido de un signo o texto se puede extender progresivamente sin encontrar algún límite determinante. La semiosis hermética establece bajo la relación de analogía/semejanza diversos criterios a través de los cuales establecer relaciones; pero es en este punto donde se presenta el problema: "en cuanto el mecanismo de la analogía se pone en marcha, no hay garantía de que se detenga ... Cada vez que 
uno crea haber descubierto alguna semejanza, esta señalará a otras en una progresión interminable" (Eco, 1995, p. 58).

En términos del mismo Eco, la semiosis hermética genera un crecimiento connotativo de "tipo canceroso", donde las asociaciones entre términos tienden a perderse en una cadena progresiva: de tal suerte que las propiedades de un término inicial (A) quedan progresivamente desvinculadas con las propiedades de un término posterior (E). Esta descripción, pero en términos de un sistema de connotación a la manera de Hjelmslev, nos muestra que el crecimiento connotativo canceroso establece asociaciones opuestas: en donde si bien un sistema de denotación (E-C) se asocia con un contenido (C2); este mismo sistema de denotación funciona como expresión (E) en relación con otro contenido (C3), que es en principio diferente y opuesto a (C2). El diagrama que utiliza Umberto Eco (1992) para ilustrar esto es el siguiente:

\begin{tabular}{|l|l|l|}
\hline C3 & $\mathrm{E}$ & \multicolumn{1}{|c}{} \\
\hline \multirow{4}{*}{} & $\mathrm{E}$ & $\mathrm{C} 2$ \\
\cline { 2 - 3 } & $\mathrm{E} / \mathrm{C}$ & \multicolumn{1}{|c}{} \\
\cline { 2 - 3 } & &
\end{tabular}

Una consecuencia de esta connotación cancerosa es la permisibilidad para establecer asociaciones indirectas e injustificadas. Es decir, permite establecer vínculos en razón de un "principio de facilidad”, a partir del cual se pueden homologar diferentes tipos de relación analógica. Pero esta posibilidad de la semiosis hermética es, precisamente, el fundamento del cáncer: se puede llegar al caso donde "de la analogía morfológica se había pasado a la analogía funcional” (Eco, 1995, p. 61). Tomando como base esta reflexión, se afirma entonces que, si el proceso de difusión mediático funciona a la manera de una semiosis hermética, entonces la construcción de sentido en las representaciones mediáticas se realiza en razón de una "falsa transitividad"; a saber, donde las relaciones propias que constituyen la funcionalidad de un objeto se le atribuyen a otro diferente en razón de la semejanza en la forma de ambos.

A fin de cuentas, caracterizar el proceso de difusión masiva de representaciones mediáticas como un proceso de semiosis hermética es, en este trabajo, solo un esbozo de una línea de trabajo sobre la cual se pueden sugerir otras líneas de investigación. Sin embargo, eso no nos impide notar algunos problemas iniciales. En principio, tendría que señalarse el problema epistemológico que supone la semiosis hermética: pues si bien en tanto semiosis genera un crecimiento de sentido, al mismo tiempo impide, como efecto de un crecimiento desproporcionado, la construcción de conocimiento.

A nivel de la información difundida en los medios, lo anterior implica que se estaría obstaculizando la formación de una autoconciencia social del presente como parte de ese conocimiento construido, pero obstaculizado por la semiosis hermética. La 
cuestión es, en todo caso, considerar que en la interpretación de las representaciones mediáticas de los medios masivos (y desmasificados) no ocurre un proceso de "semiosis ilimitada" a la manera de Peirce, en la cual los signos están en relación de interdependencia y transformación significativas; y es entonces cuando el desarrollo social de un lenguaje está determinado por un movimiento de "semiosis ilimitada”, en la cual el sentido de los diferentes signos está sometido a procesos cambiantes dentro de un "campo" específico.

La condición para que haya un proceso de semiosis es la existencia de signos, y la consecuencia de esta interrelación sígnica es epistemológica: "pues un signo, al conocerlo, nos hace conocer algo más” (Peirce, 1997, p. 213). Mientras que la semiosis hermética, de acuerdo con Umberto Eco, es un proceso de analogías donde un signo nos muestra siempre algo diferente, es decir, otros signos que se relacionan entre sí de manera progresiva. El planteamiento pragmático de Peirce muestra una clara solución a la epistemología del signo, pues el carácter ilimitado de la semiosis tiene como fin el conocimiento; pero como límite afirma el carácter trascendental de una comunidad determinada para establecer aquello que es el sentido social.

Si en los medios masivos las fronteras de un grupo y su contexto se desdibujan en lo virtual, entonces el problema de los medios masivos y electrónicos sigue vigente: ¿cuál es esa comunidad que establece los límites de sentido y desde qué mecanismos semióticos lo hace? Y en caso de ser acertada la hipótesis acerca de la semiosis hermética, cabría preguntar: ¿son las representaciones mediáticas signos o funciones de signos?

Los caminos de investigación siguen abiertos y en permanente cambio.

\section{Referencias bibliográficas}

Adorno, T. y Horkheimer, M. (2006). Dialéctica de la Ilustración. Madrid: Trotta.

Baslev, H. et al. (2009). Utopías y Globalización. México: Colegio de Sonora.

Bauman, Z. (2002). La ambivalencia de la Modernidad y otras conversaciones. Barcelona: Paidós.

Bauman, Z. (2003). Modernidad Líquida. México: Fondo de Cultura Económica.

Bourdieu, P. (1985). ¿Qué significa hablar? Madrid: Akal.

Eco, U. (2000). Tratado de Semiótica General. Barcelona: Nueva Imagen.

Eco, U. (1998). La Estrategia de la Ilusión. Barcelona: Lumen.

Eco, U. (1995). Interpretación y sobreinterpretación. Reino Unido: Cambridge University Press.

Eco, U. (1992). Los límites de la interpretación. Barcelona: Lumen.

García Canclini, N. (1995). Consumidores y Ciudadanos. México: Grijalbo.

García Canclini, N. (2000). La Globalización imaginada. México: Paidós. 
Geertz, C. (1997). La interpretación de las culturas. Barcelona: Gedisa.

Gomis, L. (1991). Teoría del Periodismo. Barcelona: Paidós.

Granja, D. (2009). Cosmopolitismo. Democracia en la Era de la Globalización. México: Anthropos/UAM.

Hacking, I. (1996). Representar e Intervenir. México: Paidós/UNAM.

Mattelart, A. (2000). Historia de la utopía planetaria. De la ciudad profética a la sociedad global. Barcelona: Paidós.

McLuhan, M. (1991). Aldea Global: transformaciones en la vida y los medios de comunicación mundiales en el siglo XXI. México: Gedisa.

McLuhan, M. (1996). Comprender los medios de comunicación: las extensiones del ser humano. Barcelona: Paidós.

Moles, A. (1974). Objeto y Comunicación. En Moles, A. Los Objetos. Buenos Aires: Tiempo Contemporáneo.

Peirce, Ch. S. (1997). Escritos Filosóficos. México: Colegio de Michoacán.

Ramonet, I. (2001). La Tiranía de la Comunicación. Madrid: Debate.

Rodrigo Alsina, M. (1979). La construcción de la noticia. Barcelona: Paidós.

Toffler, A. (2000). La tercera Ola. Barcelona: Plaza y Janés.

Toffler, A. y Toffler, H. (1996). La creación de una nueva Civilización. Barcelona: Plaza y Janés. 